\title{
Partial cystectomy and bilateral ureteroneocystostomy for resection of invasive transitional cell carcinoma involving the trigone area of the bladder in a dog - case report
}

\author{
[Cistectomia parcial e uretroneocistostomia bilateral para ressecção de carcinoma invasivo \\ de células de transição envolvendo área trigonal de bexiga em cão - relato de caso] \\ J.O. Ribeiro ${ }^{\text {}}$, M.C.N. Wittmaack ${ }^{\text {I }}$, P.R.S. Gomide ${ }^{\text {, }}$, G.L. Montanhim ${ }^{1}$, G. Sembenelli ${ }^{1}$, \\ M.G.P.A. Ferreira ${ }^{1}$, P.D. Cosentino ${ }^{2}$, A.B. de Nardi ${ }^{3}$, P.C. Moraes ${ }^{3}$ \\ ${ }^{1}$ Aluno de pós-graduação - FCAV - Unesp - Jaboticabal, SP \\ ${ }^{2}$ Médica veterinária autônoma - Jaboticabal, SP \\ ${ }^{3}$ FCAV - Unesp - Jaboticabal, SP
}

\begin{abstract}
This study aims to report the technique of partial cystectomy and bilateral ureteral reimplantation for resection of transitional cell carcinoma (TCC) in the trigone region of the bladder and the long-term follow-up in a Bernesse Mountain dog. The proposed surgical technique was considered viable and a potential treatment option for TCC in bladder trigone, with benefits regarding the prevention of urinary tract obstruction due to neoplastic growth and local removal of the primary tumor, which may limit or delay the spread of the disease even without adjuvant chemotherapy. The main disadvantages related to the described technique are ureteral stricture, intermittent cystitis and local relapse. However, the results are acceptable considering the long-term survival of 610 days in the case described.
\end{abstract}

Keywords: urinary bladder, ureteral reimplantation, urothelial carcinoma

\section{RESUMO}

Esse estudo tem como objetivo relatar a técnica de cistectomia parcial e reimplantação uretral bilateral para ressecção de carcinoma de células de transição em região trigonal de bexiga e seguimento clínico de cão da raça Bernesse Mountain. A técnica cirúrgica proposta foi considerada viável e opção potencial de tratamento com benefícios na prevenção de obstrução de trato uretral devido a crescimento neoplásico e remoção local de tumor primário que pode limitar ou retardar a disseminação da doença mesmo sem quimioterapia adjuvante. A principal desvantagem relatada em relação à técnica descrita são constrição uretral, cistite intermitente, e relapso local. No entanto, os resultados são aceitáveis levando em consideração a sobrevida a longo prazo de 610 no caso descrito.

Palavras chave:bexiga urinária, reimplantação ureteral, carcinoma urotelial

\section{INTRODUCTION}

Transitional cell carcinoma (TCC), also referred to as urothelial carcinoma, is the most common presentation of neoplasia in the urinary bladder of dogs. They are invasive neoplasias, often located in the trigone region of the bladder and urethra. Clinical signs resemble those seen in animals with lower urinary tract infection. Several factors have already been associated with the development of TCC in dogs, among them, the exposure to exogenous chemical agents, obesity, breed and sexual predisposition (Fulkerson and Knapp, 2015).

Distant metastases detected at the time of diagnosis are described in $20 \%$ cases of TCC. Medical images of the urinary tract allow the therapeutic planning as well as follow-up of the established therapeutic response, but it is the histopathological examination that provides the definitive diagnosis (Salnier-Troff et al., 2008; Boston and Singh, 2014).

Recebido em 24 de abril de 2017

Aceito em 10 de outubro de 2017

E-mail: juliana.oribeiro@yahoo.com.br 
Surgical treatment may be indicated for both diagnostic and therapeutic purposes. During surgery, preventive measures are necessary to avoid "neoplasm seeding" in neighboring structures and abdominal wall. Because of its invasive potential, complete excision of the mass may not be possible. Resection of the bladder trigone and proximal urethra has contraindications, given the high rate of postoperative complications. Therefore, other techniques of total cystectomy and urinary diversion have been suggested, but still, postoperative complications are described (McLaughlin, 2011; Saeki et al., 2015).

Treatments such as chemotherapy and/or specific inhibitors in adjuvant therapy are approaches that allow a longer disease-free interval and survival of treated patients (Fulkerson and Knapp, 2015). The present report aims to describe the technique of partial cystectomy and bilateral ureteroneocystostomy to control CBT of the bladder, which exists as a solution for local control of the neoplasia. To date, one patient has reached 610 days disease free.

\section{CASE REPORT}

A Bernese Mountain dog, nine years old, $43 \mathrm{~kg}$, with a history of dysuria and intermittent hematuria, was checked in at the Veterinary Hospital "Governador Laudo Natel" of the State University of São Paulo-Jaboticabal, presenting a history of treatment for lower urinary tract infection three Months prior. The patient was submitted to clinical evaluation and laboratory tests (complete blood count, renal and hepatic panel and urinalysis) that were within normal values. Abdominal ultrasound showed a structure with dimensions of $3.0 \mathrm{~cm} \times 2.5 \mathrm{~cm}$ in the trigone region of the bladder, without urethral involvement (Figure 1).

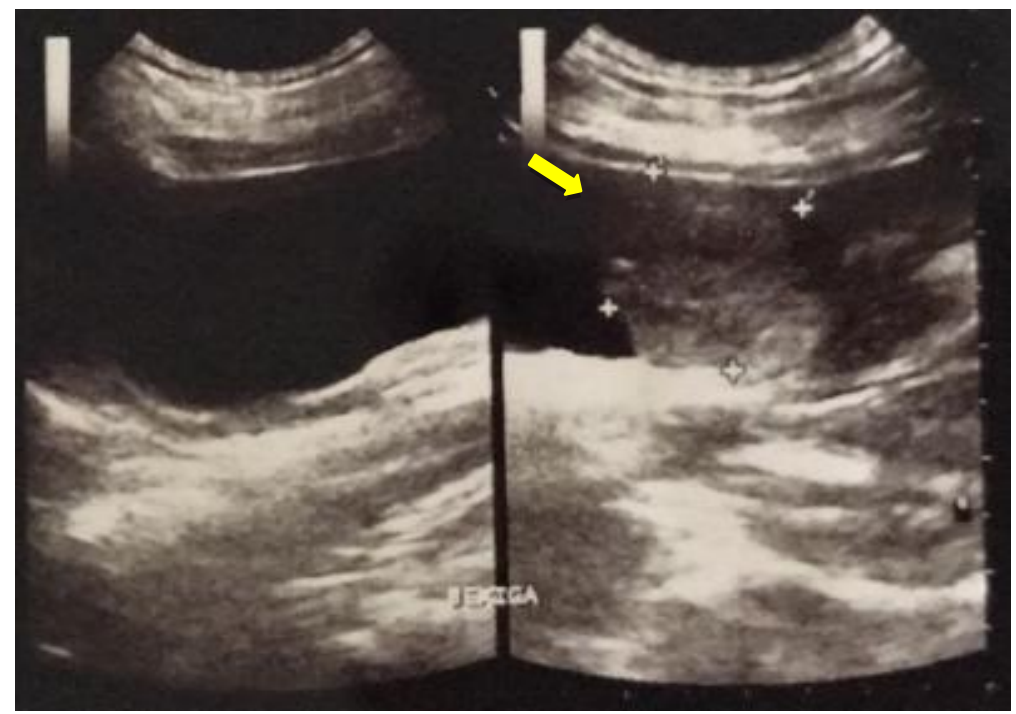

Figure 1. Abdominal ultrasound image of the structure with dimensions of $3.0 \mathrm{~cm} \times 2.5 \mathrm{~cm}$ in the trigone region of the bladder, without urethral involvement. Medical Imaging Department - UNESP, Jaboticabal Campus.

Therefore, bladder lavage and subsequent cytology of the fluid were performed, and such examination was considered inconclusive. A contrast radiographic examination (Figure 2) showed a rounded structure in the trigone region of the bladder adhered to the wall, which was projected towards the lumen. Imaging examinations showed no involvement of regional lymph nodes. Thoracic radiographs performed on three projections did not show the presence of metastases. Surgical intervention was indicated.

Laparotomy was performed in the ventral midline, location and bladder exposure. During the physical exam and palpation of the bladder, the presence of a firm, irregular and adherent structure was found in the trigone region of the bladder of approximately $3 \mathrm{~cm}$ in diameter (Figure 3A). Cystotomy was performed on the 
dorsal surface of the urinary bladder for inspection of the structure. The mass involved the left ureter and bladder neck (Figure 3B). The surgical resection was then chosen, respecting the margin of $1 \mathrm{~cm}$ on the sides. Due to the extension of the lesion, the ureteral ostia were compromised, the left wrapped by the mass and the right compromised by the surgical margin, being necessary, in addition to partial cystectomy, resection of both ureters and posterior reimplantation in the ventral wall of the bladder. Resection comprised about 40 to $50 \%$ of all bladder tissue. For this, two transmural tunnels were performed with hemostatic forceps, on the ventral surface of the bladder, where tension is lower.

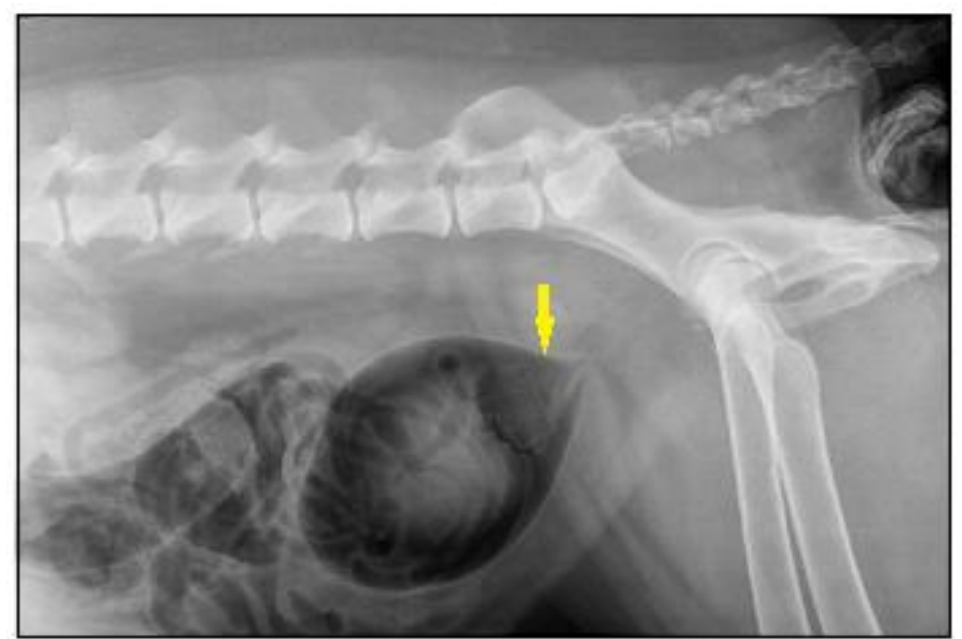

Figure 2. Radiographic image of the double contrast cystography, showing a structure in the trigone region of the bladder (arrow) - Medical Imaging Department - UNESP, Jaboticabal Campus.

A longitudinal (spatula) incision of approximately $0.5 \mathrm{~mm}$ was made in the distal portion of the remaining ureters to increase the circumference of the ostium (Figure $3 \mathrm{C}$ and D). Two urethral number 6 catheters were used to locate the urethra (Figure 3C) and a number 4 urethral catheter were used to identify the created ureteral ostia (Figure 3D). Caprofyl ${ }^{\circledR}$ 4-0 monofilament synthetic absorbable suture was used. The first stitch was made at the apex of the incision and the rest of the anastomosis was made with single interrupted suture between the bladder and the ureteral mucosa until the entire ureteral border was properly positioned within the lumen of the organ. Cystorrhaphy was performed with Caprofyl® 2-0, with a single interrupted suture pattern. After omentopexy, the conventional method of laparorrhaphy was performed.

The material collected was sent to histopathological analysis that was compatible with invasive transitional cell carcinoma, presence of lymphovascular invasion and tumor free margins. At this time, the clinical stage of the patient was defined as T2N0M0. However, the owner chose not to perform additional adjuvant treatments after a high, such as antineoplastic chemotherapy and COX-2 inhibitors. In the postoperative period, drug therapy was instituted with Cephalexin $30 \mathrm{mg} / \mathrm{kg}$, Ranitidine $2 \mathrm{mg} / \mathrm{kg}$, Tramadol Hydrochloride $3 \mathrm{mg} / \mathrm{kg}$, Tipirone $25 \mathrm{mg} / \mathrm{kg}$ and Firocoxib $5 \mathrm{mg} / \mathrm{kg}$. A urethral catheter was maintained to prevent bladder repletion for five days, which was removed by the patient through a bite leaving a fragment inside the bladder. Ultrasound examination showed diffuse and irregular thickening of the bladder wall, suggesting a postoperative inflammatory process. In the dorsal wall, a hypoechogenic area with a slight formation of acoustic shadow was observed, suggesting presence of a foreign object in the bladder lumen. After episodes of worsening of the clinical Figure, with $432 \mathrm{mg} / \mathrm{dL}$ of urea and $8.6 \mathrm{mg} / \mathrm{dL}$ of creatinine and presence of bacterial cystitis, despite the effective support treatment, cystoscopy was indicated, after 45 days of surgery, for removal of the foreign body and verification of the patency of the ureteral ostium (Figure 4). 


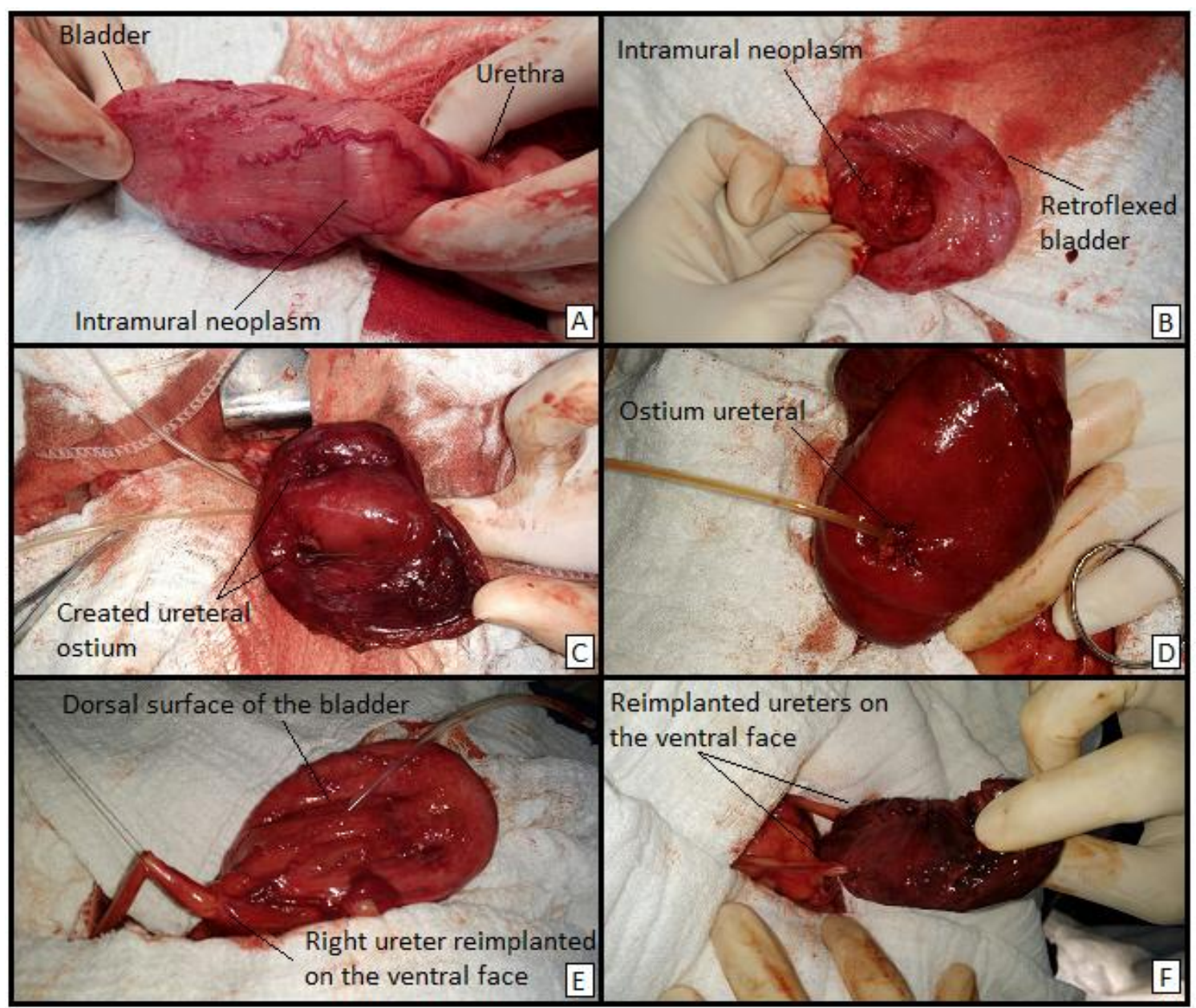

Figure 3. Transoperative images of partial cystectomy and ureteroneocystostomy in dogs. (A) Urinary bladder with intraluminal mass in the trigone region of the bladder. (B) Intraluminal tumor after incision on the dorsal side of the bladder. (C) Ureteral ostia created after bladder ureteral reimplantation. (D) After "spatulation" of the ureter, anastomosis of the ureter to the bladder mucosa. (E) Reimplantation of the ureter on the ventral surface of the bladder. (F) Ureters reimplanted on the ventral face of the bladder. Department of Small Animal Surgical Clinic - UNESP, Jaboticabal Campus.

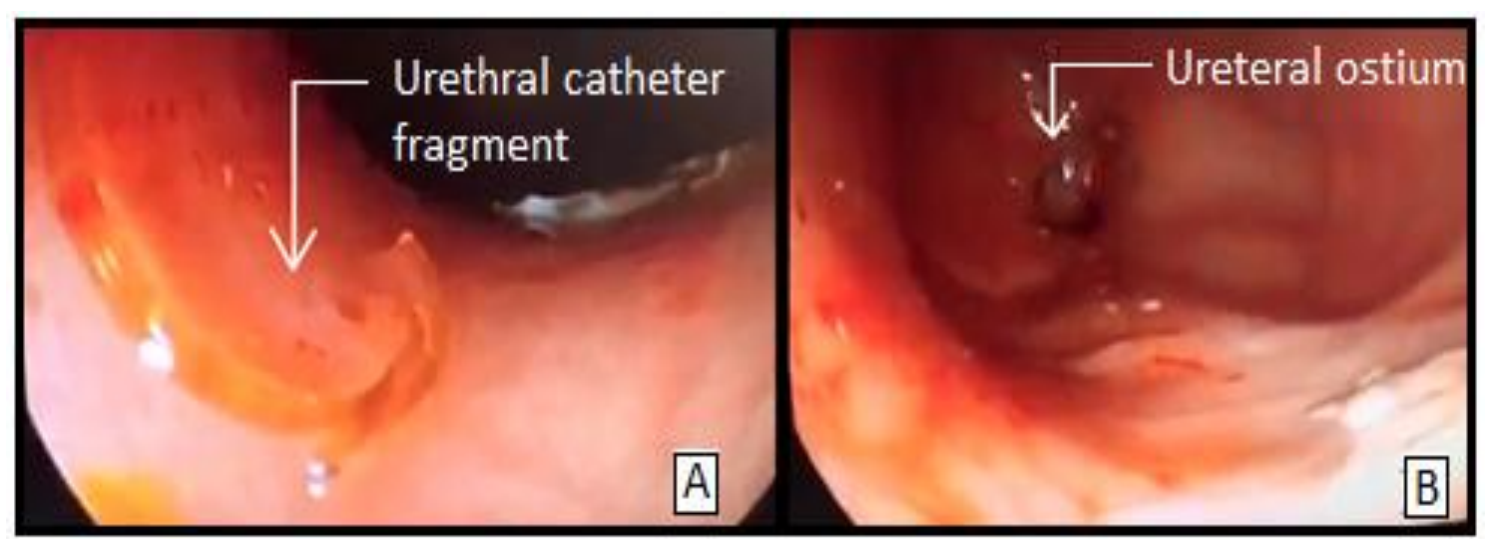

Figure 4. Transurethral cystoscopy in the dog. (A) Fragment of urethral catheter in the urinary bladder. (B) Ureteral ostium created after reimplantation of the ureter into the urinary bladder. 
Ultrasonographic images and urinalysis were performed every month. On the 90th day, during ultrasound examination, a hypoechoic image with a slight formation of acoustic shadow was observed in the middle third of the bladder dorsal wall, being adhered to the wall $(1.19 \mathrm{~cm}$ of dimension) with discrete vascularization. A follow-up was suggested to owners because of the possibility of tumor recurrence. The presence of discrete hydronephrosis with dilatation of the proximal ureter and increased echogenicity of the ureteral wall and renal pelvis were also seen in the left kidney. These ultrasonographic results were compatible with chronic nephropathy and mild hydronephrosis, which, at the day 210, evolved to loss of renal parenchyma and dilation of the proximal left ureter, compatible with hydroureter. At this time, the patient was restaged and no important change was observed. Surgical reintervention was performed, where the presence of left ureteral obstruction by a cicatricial reaction was observed and confirmed by histopathological examination. Nephrectomy of the left kidney was performed due to severe hydronephrosis. The patient presented excellent postoperative recovery and remained stable until the present moment (610 days after the first surgical intervention), being monitored monthly for clinical staging.

\section{DISCUSSION}

Clinical signs of TCC in dogs are mixed up with signs of lower urinary tract inflammation / infection and these signs may be present weeks to months before diagnosis. Antimicrobial therapy can cause reduction or temporary resolution of clinical signs. Patients with TCC are at high risk of developing secondary urinary tract infections, and the bacteria involved are increasingly resistant to antibiotic treatment (Fulkerson and Knapp, 2015). In the case reported, signs of cystitis delayed the diagnosis of cancer. In addition, although complete surgical resection performed, during postoperative follow-ups, signs of cystitis and chronic reinfection were still intermittent in the patient. Antimicrobial therapy with Cephalexin $30 \mathrm{mg} / \mathrm{kg} / \mathrm{bid}$ was instituted for 30 days. However, palliative treatments that do not remove TCC from the bladder will also result in a patient predisposed to chronic urinary tract infections (Salnier-Troff et al., 2008).
Local tumor recurrence is a frequent complication after bladder TCC resection. The reasons related to it are presence of residual tumor at the site of resection, neoplastic transformation of the remaining bladder mucosa and implantation of tumor cells into the surgical wound. Incomplete excision is obviously a significant risk factor and macroscopic observation may not be sufficient to delineate the tumor extent. In the case described, free margins were obtained according to histopathological report, and the macroscopic safety margin delimited in the intraoperative period had one centimeter. This factor, associated with the patient's clinical condition of renal failure that was not postoperative, were determinant for a choice of non-performance of antineoplastic chemotherapy and COX-2 inhibitory antiinflammatory drugs.

Factors such as an agent of exogenous chemical agents, obesity, race, and sexual predisposition are associated with the development of CBT in dogs (Fulkerson and Knapp, 2015). The transformation of the remaining bladder mucosa is another cause of the cancer recurrence. This phenomenon occurs as a result of the same tumor conditions that caused the original tumor. The mucosa located around the tumor is at risk of being exposed to the same dose of carcinogens. This development is also known as the "cancer field effect" where the entire bladder lining undergoes neoplastic transformation in response to carcinogenic agents. Seeding and intraluminal implantation of tumor cells after surgical manipulation are also related to cancer recurrence (Boston and Singh, 2014). In the present report it is possible to affirm that up until 90 days of postoperative, there was no local recurrence of the tumor as visualized in cystoscopy images of the bladder and ultrasonographic follow-up. After the second surgical intervention, 210 days after partial cystectomy, it was possible to verify that there was no tumor recurrence by histopathological analysis. From this period, ultrasonographic control has been performed, without evidence of abnormal tissue growth.

The main postoperative complications of the ureteroneocystostomy technique include ureteral stenosis at the anastomosis site, hydroureter and hydronephrosis as a result from ureteral stenosis or stoma, causing the obstructive disease. 
Hydronephrosis and hydroureter may be temporary and secondary to postoperative edema and could last up to six weeks (Reichler et al., 2012). On the 10th postoperative day, there were signs of hydronephrosis and hydroureter in the ultrasound; however, on the 25th day, there was an improvement in these alterations. However, on the 90th postoperative day, ultrasound imaging indicated the presence of mild hydronephrosis in the left kidney, which was progressively evolving. There is a relatively high incidence of stenosis at the site of ureteral anastomosis because of the small diameter of the ureter (Reichler et al., 2012, Wormser et al., 2015). Ultrasonographic images were suggestive of stenosis at the base of the ureter implantation in the left site of the bladder because of cicatricial reaction, and it was confirmed by histopathological examination in the second surgical intervention.

Partial cystectomy and ureteroneocystotomy are feasible techniques for treatment of bladder TCC in dogs, with the objective of delaying the evolution of the disease and preventing ureteral and urethral obstruction. According to SalnierTroff et al. (2008), although distant metastatic disease is worrisome, in the majority of dogs with bladder TCC, the primary location of the tumor is the most common cause of death. The main disadvantages of the described technique are associated with ureteral stenosis, intermittent cystitis and local cancer recurrence. However, the results obtained were satisfactory regarding the disease-free survival of 610 days, associated with only surgical intervention.

\section{CONCLUSION}

Partial cystectomy and bilateral ureteroneocystotomy are potential treatment options for TCC in the dog's bladder trigone.

\section{REFERENCES}

BOSTON, S.; SINGH, A. Total cystectomy for treatment of transitional cell carcinoma of the urethra and bladder trigone in a dog. Vet. Surg., v.43, p.294-300, 2014.

FULKERSON， C.M.; KNAPP， E.D.W. Management of transitional cell carcinoma of the urinary bladder in dogs: a review. Vet. J., v.205, p.217-225, 2015.

MCLAUGHLIN, M.A. Complications of lower urinary tract surgery in small animals. Vet. Clin. Small Anim., v.41, p.889-913, 2011.

REICHLER, I.M.; SPECKER, C.E.; HUBLER, M. et al. Ectopic ureters in dogs: clinical features, surgical techniques and outcome. Vet. Surg., v.41, p.515-522, 2012.

SAEKI, K.; FUJITA, A.; FUJITA, N. et al. Total cystectomy and subsequent urinary diversion to the prepuce or vagina in dogs with transitional cell carcinoma of the trigone area: a report of 10 cases (2005-2011). Can. Vet. J., v.56, p.73-80, 2015.

SALNIER-TROFF, F.G.; BUSONI, V.; HAMAIDE, A.A Technique for resection of invasive tumors involving the trigone area of the bladder in dogs: preliminary results in two dogs Vet. Surg., v.37, p.427-437, 2008.

WORMSER, C.; CLARKE, D.L.; ARONSON, L.R. End-to-end ureteral anastomosis and double-pigtail ureteral stent placement for treatment of iatrogenic ureteral trauma in two dogs. J. Am. Vet. Med. Assoc., v.247, p.92-97, 2015. 